\title{
Mutations in NR4A2 associated with familial Parkinson disease
}

W Le, P Xu, J Jankovic, H Jiang, S H Appel, R G Smith \& D K Vassilatis

Nat. Genet. 33, 85-89 (2003).

On page 86, right column, second paragraph, the first line should read, "We carried out haplotype analysis for three available pedigrees...” 